\title{
Nanomagnetite and Chitosan Affect Seed Germination and Growth of Wheat (Triticum Aestivum L.)
}

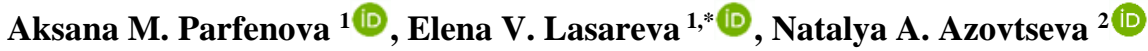 \\ 1 Lomonosov Moscow State University, Chemical Faculty, Russia \\ 2 Dokuchaev Soil Science Institute, RAS, Moscow, Russia \\ * Correspondence: elasareva@ya.ru;
}

Scopus Author ID 26642537300

Received: 22.10.2020; Revised: 15.11.2020; Accepted: 18.11.2020; Published: 22.11.2020

\begin{abstract}
Iron deficiency is one of the limiting factors of plant growth. In recent years nanotechnology has attracted attention to producing forms of iron that are available to plants. Chitosan, which is widely used in agriculture due to its unique properties, has metal-binding abilities. We decided to study nanomagnetite and chitosan's combined action to improve seed germination and growth of wheat (Triticum aestivum L.). The thumbnail method was used in the study. The seeds were treated with magnetite suspension and chitosan solutions before planting. An increase in plant growth, root, and shoot length of plants was found in all seed treatment methods (chitosan, nanomagnetite, and combined action). This increase was significantly dependent on the concentration of chitosan. However, chitosan and magnetite combination was 1.3 times more effective for seed germination than pure chitosan or magnetite. A mechanism based on chitosan's ability to promote the better transfer of iron ions to plants is proposed. However, further investigation for the optimization of chitosan/magnetite proportions for improving seed growth is required.
\end{abstract}

Keywords: nanomagnetite; chitosan; seed germination; wheat.

(C) 2020 by the authors. This article is an open-access article distributed under the terms and conditions of the Creative Commons Attribution (CC BY) license (https://creativecommons.org/licenses/by/4.0/).

\section{Introduction}

Iron is an essential trace element for almost all living organisms due to its significant role as an energy carrier within the plant [1]. It is a constituent of certain enzymes and proteins. Also, iron is crucial for chlorophyll formation in photosynthesis and is involved in nitrogen fixation [2]. Iron deficiency is a limiting factor in plant growth. Although iron is present in high quantities in soils (2-3\%), its availability to plants is usually very low [3]. Plants can uptake iron in their ionic forms, such as $\mathrm{Fe}^{2+}$ (ferrous) and $\mathrm{Fe}^{3+}$ (ferric). However, the $\mathrm{Fe}^{2+}$ form is physiologically more significant for plants. Iron is insoluble at neutral and high $\mathrm{pH}$ and is therefore unavailable for plants in alkaline and calcareous soil. The way to prevent the $\mathrm{Fe}^{2+}$ form oxidation is its stabilization with chelating agents (EDTA, DTPA, amino acids, humic and fulvic acids). Recently, a positive effect of highly dispersed magnetite $\left(\mathrm{Fe}_{3} \mathrm{O}_{4}\right)$ on the germination and growth of wheat was shown [4]. Bio-inorganic nanoparticles are widely present in living organisms of all levels and types of organization. Biogenic generation of nanophase magnetic oxides is important from a fundamental viewpoint and meaningful for many applications [5-7]. However, only little is known about the joint action of magnetite in combination with organic substances. 
Considering various organic substances to be applied with magnetite, it is interesting to focus on chitosan. Chitosan $(\mathrm{Ch})$ is a well-known agent to protect plants against viruses and bacteria. Owing to its nontoxic, biodegradable, and nonpollution characteristics, it may be considered a new type of green pesticide. The unique properties may play an important role in agriculture, preserving crop yield, and quality [8-11]. Moreover, Ch is known for its ability to form complexes with metal ions [12].

In that connection, the study of the role of bio-inorganic nanocomposites combined with $\mathrm{Ch}$ to reduce the negative impact of diseases on crops' quality has growing interest. In the present study, we investigated the effects of chitosan, highly dispersed magnetite, and their combined action on wheat germination and seedling growth (Triticum aestivum L.).

\section{Materials and Methods}

\subsection{Materials.}

Natural polysaccharide chitosan $(\mathrm{Ch})$ of $\mathrm{Mw} 300 \mathrm{kDa}$, with a deacetylation degree 8285\%, was prepared in BioProgress Technology Ltd, Schelkovo used in the chloride form. Ch concentration was varied from 0 to $0.04 \%$. The concentration of magnetite prepared by reaction [13] was kept constant (20 g/l). The average particle size was $400 \mathrm{~nm}$.

\subsection{Methods.}

\subsubsection{Thumbnail method.}

The study was made by the thumbnail method (Fig. 1). Before sowing, the collected wheat seeds $(0,035 \pm 0,003 \mathrm{~g})$ were placed in $10 \mathrm{ml}$ bulbs, where $3 \mathrm{ml}$ of magnetite suspension and different quantities of chitosan solutions were added. The seeds were soaked for $4.5 \mathrm{~h}$. Seeds soaked in water were used as control. Nine seed holes of about $3 \mathrm{~cm}$ depth were made in each pot. Nine seeds previously treated/nontreated with chitosan and magnetite were inserted into the holes in soil (sod-podzolic soil - Eutric Albic Retisol (Moscow region) [14]. The seed holes were closed, and the pots were kept at room temperature $\left(21-23^{\circ} \mathrm{C}\right)$. Sowing seeds were watered with $10 \mathrm{ml}$ of water every day during the whole time of the study. The influence of $\mathrm{Ch}$ and magnetite additions on seed germination was estimated by seeds viability in three days. The estimations of shoot height, root length, and weight of plants were made a week after plant sowing. The estimation of the studied characteristic was made based on the average value concerning nine planting seeds.

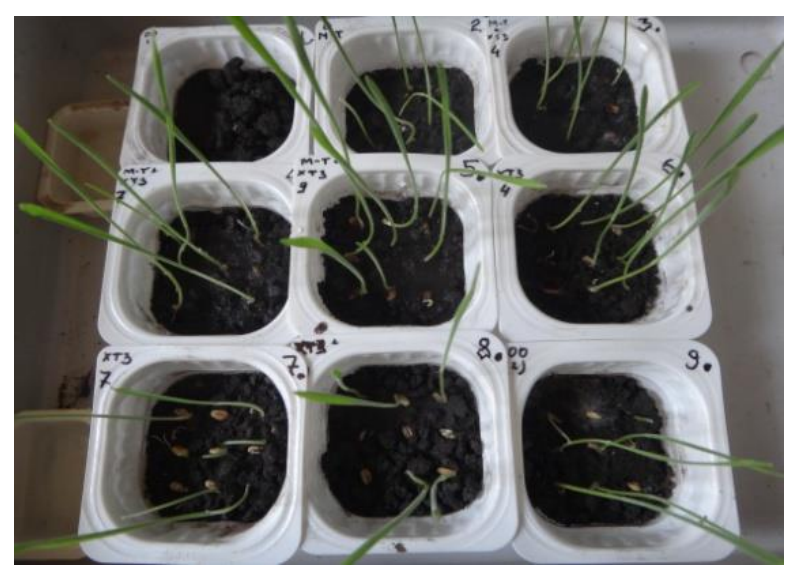

Figure 1. Thumbnail method for the study of plant development. 


\subsubsection{Preparation of magnetite.}

Magnetite was prepared by the reaction of ammonium solution with the mixture of ferric chloride and ferrous chloride under intensive stirring [13]:

$$
\mathrm{FeCl}_{2}+2 \mathrm{FeCl}_{3}+8 \mathrm{NH}_{3} \rightarrow \mathrm{Fe}_{3} \mathrm{O}_{4}+8 \mathrm{NH}_{4} \mathrm{Cl}+4 \mathrm{H}_{2} \mathrm{O}
$$

The average particle size of magnetite was determined by the LALLS method (Low Angle Laser Light Scattering) [15].

\subsubsection{Drop shape analysis (contact angle).}

Drop shape analysis (DSA) was used for determining the contact angle from the shape of the droplet. Contact angle, $\theta$ (theta), is a quantitative measure of a solid's wetting by a liquid. The contact angle is geometrically defined as the angle formed by a liquid at the three-phase boundary where a liquid, gas, and solid intersect. A drop of distilled water or chitosan solutions was placed onto a Teflon plate to determine a contact angle. The drop shape was recorded with a photo camera and treated by the software "Promer". The accuracy of the method is $\pm 1^{\circ}[15]$.

\section{Results and Discussion}

\subsection{Results.}

3.1.1. Effects of magnetite and chitosan on seed germination.

It was shown that the treatment of seeds with magnetite without chitosan gave practically the same results in seed germination compared with the control test ones. In the case of seeds treatment by chitosan without magnetite, the highest seed germination was observed at high Ch concentration $(0.04 \%)$. At the same time, the decrease of such value was determined at low Ch concentrations. The joint action of chitosan and magnetite is 1.3 times more effective in seed germination, compared to the control test at the concentration of Ch $0.01 \%$ (Fig.2).

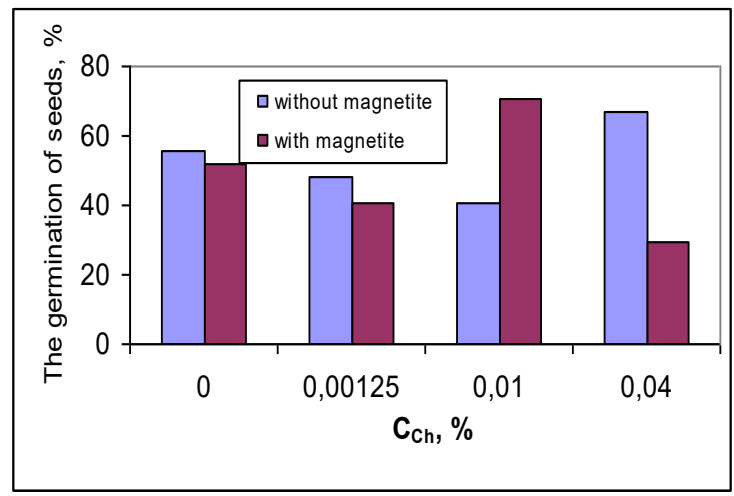

Figure 2. Influence of chitosan and nanomagnetite on germination of treated/nontreated seeds.

3.1.2. Effects of magnetite and chitosan on shoot and root length of plants.

The increase of shoot length (1.6 times) (Fig. 3) as well as of the root length of plants (1.4 times) (Fig. 4) was observed when seeds were treated with the maximum chitosan concentration $(0.04 \%)$ without nanomagnetite. 


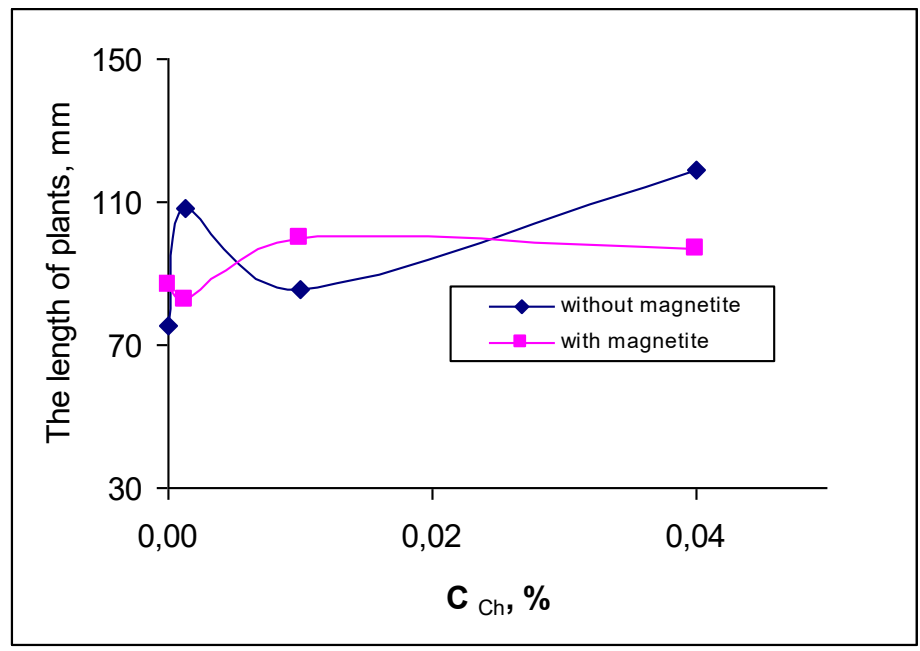

Figure 3. Influence of chitosan and nanomagnetite on the shoot length of the plant.

The combined action of magnetite and chitosan increased plants' shoot and root growth by 1.3 times and by 1.2 times, correspondingly. The treatment with nanomagnetite without chitosan gave an increase in shoots and root length by about 1.2 times.

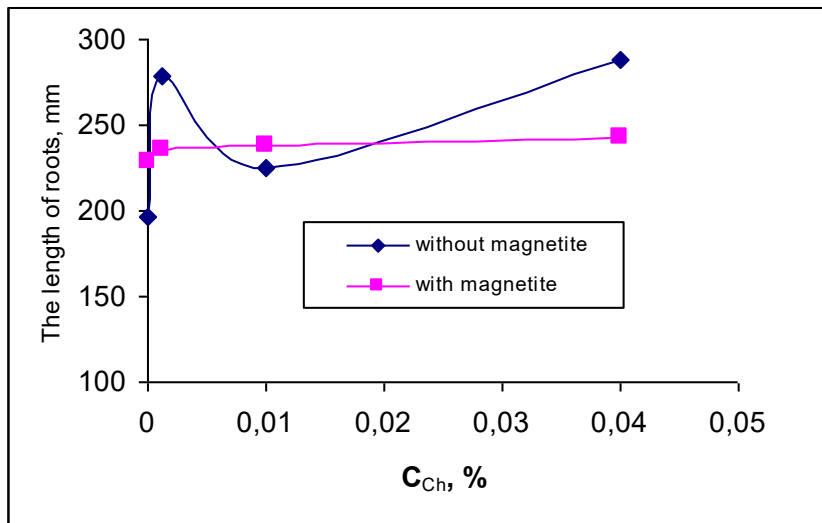

Figure 4. Influence of chitosan and nanomagnetite on the root length of the plant.

3.1.3. Effects of magnetite and chitosan on the weight of sprouted wheat.

The weight of sprouted wheat did not depend much on the combined action of $\mathrm{Ch}$ and magnetite (Fig. 5), but a slight increase in the average weight (1.2 times) was shown after the treatment of seeds with chitosan without nanomagnetite.

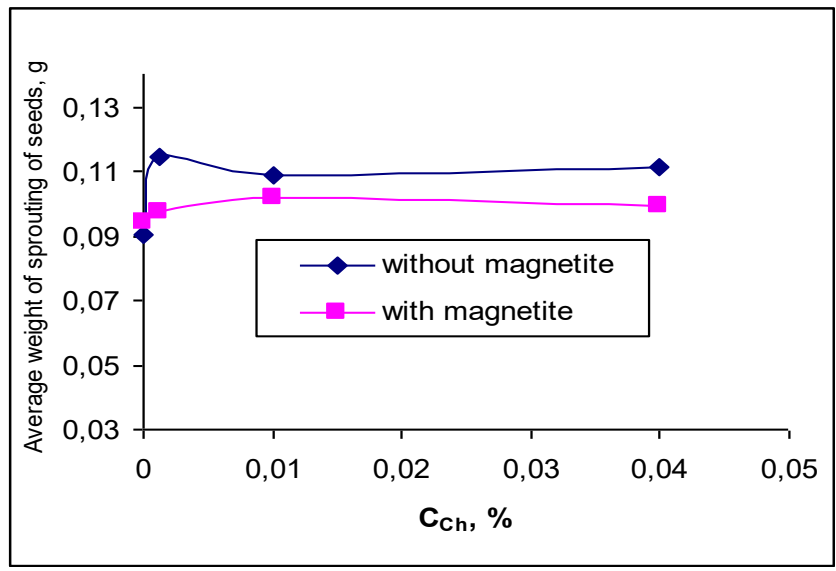

Figure 5. Influence of chitosan and nanomagnetite on the weight of sprouted wheat. 


\subsection{Discussion.}

Recent research has discovered several compounds that affect plant development; nevertheless, their roles are less understood, especially the combined role of some compounds. In our work, we try to study the combined action of an organic substance (chitosan) and an inorganic substance (nanomagnetite). Our choice was based on the positive effects of each of these agents on the growth of plants.

Iron is included in the composition of the plant in an amount of $0.08 \%$. It is transported from the roots up to other parts of the plant by xylem in the form of a Fe-citrate complex. In most cases, iron's role is related to its ability to pass from the oxidized form $\left(\mathrm{Fe}^{3+}\right)$ to the reduced form $\left(\mathrm{Fe}^{2+}\right)$ and back. Iron is a part of the catalytic centers of many redox enzymes. The form of new groups is a part of such enzymes as cytochromes, cytochromoxideza, nitrate, and nitrite reductase. Iron is also necessary for the formation of chlorophyll. In this case, iron catalyzes the formation of precursors of chlorophyll: aminolevulinic acid and protoporphyrins. It is assumed that iron plays a role in the formation of chloroplast proteins. With a lack of iron, there are no conditions for forming such important components of chloroplasts as cytochromes, ferredoxin, and some others [16]. The cytochrome system is a necessary component of the respiratory and photosynthetic electron transport chain. When there is not enough iron, both of these important processes are inhibited [17, 18].

Although total $\mathrm{Fe}$ is generally high in soil and varies in the range of 1 to $5 \%$ of its mass, the magnitude of its available fraction is generally very low [19-20]. Iron in the soil exists in ferrous $\left(\mathrm{Fe}^{2+}\right)$ and ferric $\left(\mathrm{Fe}^{3+}\right)$ forms. Soil $\mathrm{pH}$ and the aeration status of the soil determine which form predominates. Ferric iron compounds have low solubility in the soil solution, and conditions that favor these compounds' formation decrease iron availability [21]. The formation of available forms of soluble iron complexes that reach plant roots may be increased by interacting with an organic substance. Up to $21.5 \%$ of the global organic carbon is associated with the reactive forms of $\mathrm{Fe}$ in soils and sediments [22, 23].

Conversely, the formation of solid organic matter associated with minerals can reduce the mobile forms of iron and its absorption by plants [24]. An imbalance between the solubility of iron in soil and the demand for iron by the plant is the primary reason for iron deficiency (interveinal chlorosis) of the new leaves. The introduction of iron into the soil does not lead to an expected biological effect due to its rapid transition to an oxidized form that is inaccessible to plants. Due to the revealed biological activity of iron compounds, foliar feeding with solutions of organic (mainly chelates) or inorganic iron compounds is the most effective method for increasing crop yields [25].

An urgent issue is the use of various iron forms (nanoform and ionic) to improve the sowing qualities of seeds and increase productivity. Especially, nanotechnologies have become promising in agricultural systems. Nanoparticles have a high degree of bioavailability; they influence the structure and function of the photosynthetic apparatus in plants, increasing the chlorophyll concentration [26, 27]. However, few studies were conducted on how nanoparticles affect plant growth and development [28, 29].

Having mentioned above the role of organic matter on the migration of iron ions, we should consider the organic substance used in our study. Chitosan is a natural biopolymer consisting of glucosamine and $N$-acetyl chains and is wildly used in agriculture $[30,31]$. It can be obtained by deacetylation of chitin; it is present and easily extracted from the fungal cell wall and crustacean shells. Differences in the structures of $\mathrm{Ch}$ and chitin, namely the presence 
of Ch amino groups, are the base of the antimicrobial activity of chitosan compared with chitin that does not show any antimicrobial activity. Several mechanisms explain the antimicrobial and antifungal activity of chitosan. Protonated amino groups can establish electrostatic interactions between chitosan cationic amino groups and negatively charged substances such as $\mathrm{N}$-acetylmuramic acid, sialic acid, and neuraminic acid present on the bacterial cell wall. $\mathrm{Ch}$ can increase the membrane permeability leading to the leakage of intracellular substances and pathogen growth inhibition [32-37]. There is an opinion that $\mathrm{Ch}$ antimicrobial activity consists in the fact that $\mathrm{Ch}$ can induce plants to produce defense enzymes (chitosanases, $\beta$-glucanase, lipoxygenases) with antimicrobial activity and stimulating the generation of reactive oxygen species [38]. Another proposed mechanism of antimicrobial protection is the binding of chitosan with microbial DNA, which leads to the inhibition of the mRNA and protein synthesis via the penetration of chitosan into the nuclei of the microorganisms. Taking into account the excellent metal-binding capacities of $\mathrm{Ch}$, a possible explanation of antimicrobial activity of Ch may be the chelation of metals, suppression of spore elements, and binding to essential nutrients to microbial growth [39-41].

One of the most important bioactivities of chitosan is the stimulation of seed germination. As was shown for maize and ajowan seeds, priming with chitosan stimulates plant growth, root length, the weight of plants, increases the crop yields and alleviates the harmful effect of abiotic stress on plant growth (under salt stress) [42, 43]. The application of chitosan is one way to decrease the negative effect of abiotic stress and improve the seed germination and growth of wheat seedlings [44].

In recent years there has been an increased interest in using chitosan nanoparticles in agronomy as a comprehensive strategy towards productivity and plant protection [45-47]. Such an approach is based on specific properties of nanoparticles that enhance their penetration on the plant cell wall, increasing the agrochemical uptake. Moreover, the possibility of encapsulating agrochemicals in chitosan nanocarriers shields the toxic effect of the free agrochemicals on the plant. The study of the effect and mechanism of chitosan nanoparticles on the germination and seedling growth of wheat (Triticum aestivum L.), showed that the growth-promoting effect is observed at a lower concentration $(5 \mu \mathrm{g} / \mathrm{mL})$ compared with chitosan $(50 \mu \mathrm{g} / \mathrm{mL})$ [48]. The combined use of chitosan with other agents is one of the most promising modern agronomy areas [49-51]. It should be added to all the advantages of chitosan that, unlike pesticides, it cannot contaminate ecosystems, possesses such properties as biocompatibility and biodegradability, and has low-cost production.

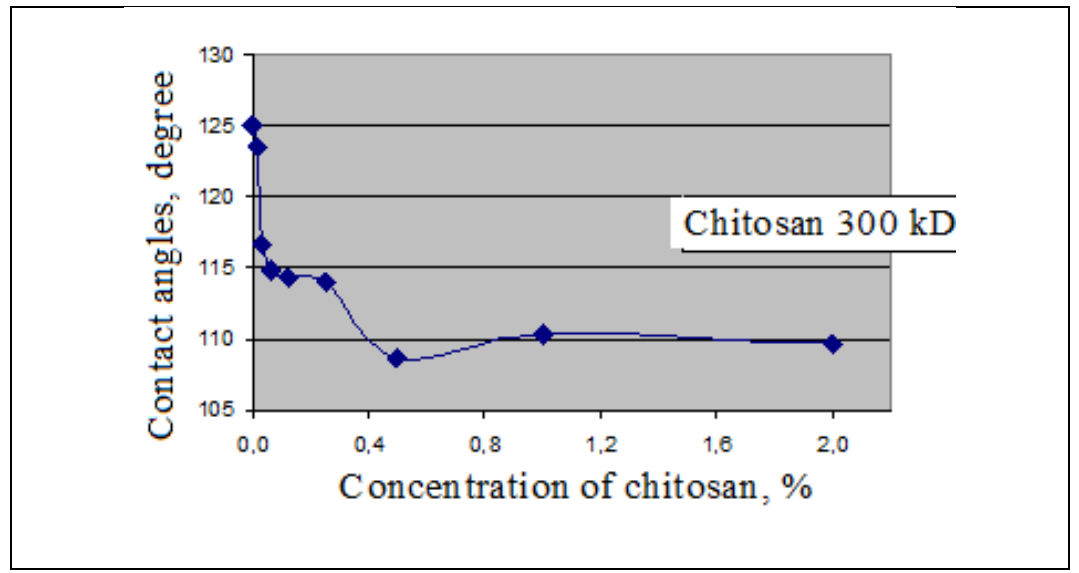

Figure 6. Contact angles of chitosan solutions on Teflon plate. 
It was shown that chitosan and magnetite's joint action is 1.3 times more effective in seed germination than the control test. Whereas the seed treatment with the only chitosan shows a slight increase in seeds germination and the treatment with magnetite did not show positive results. All seed treatment methods (chitosan, magnetite, and joint action of magnetite and chitosan) show an increase in plant growth, root length, and plants' weight. It was found that this increase is extremely dependent on the concentration of chitosan. Our data on the concentration of chitosan, which has the maximum effect on plant growth, coincide with the results presented in [48]. It is possible to assume that concentration but molecular weight, degree of acetylation, $\mathrm{pH}$, and other factors might affect Ch's biological activity. Because the action of $\mathrm{Ch}$ begins with interaction with the seed surface, one of the approaches to the mechanism of interaction was the study of the hydrophilic-hydrophobic properties of $\mathrm{Ch}$ solutions. As we can see from Fig. 6, due to the measurement of Ch solutions' contact angles on the Teflon plate, $\mathrm{Ch}$ in the studied concentration range (0-0.05\%) has hydrophilic properties. The tendency to hydrophobization is observed when the Ch concentration is higher than $0.1 \%$. That proposes the interaction of $\mathrm{Ch}$ with structure polysaccharides of seed surfaces, coved with a biofilm.

Iron ions that stabilize the magnetite particles can form a complex with $\mathrm{Ch}$. An increase in antimicrobial activity was found when chitosan binds to metal ions through nitrogen or oxygen [52]. The zeta-potential of such $\mathrm{Ch}-\mathrm{Fe}$ complexes will be higher than zeta-potential of $\mathrm{Ch}$, which ensures stronger electrostatic interaction between $\mathrm{Ch}$ and negatively charged cell walls. It was found that the reduced size and higher zeta potential of $\mathrm{Ch}$ nanoparticles resulted in their higher antibacterial activity [45]. Early we found that copper ions introduced into the soil and chitosan did not remain in the soil due to the formation of a complex with chitosan but penetrated plants [53]. It may be proposed that one of the functions of chitosan, when combined with magnetite, can be associated with facilitating iron ions to enter the plant cells [54]. On the other hand, magnetite particles flocculated by chitosan may better interact with seed polysaccharides [49]. However, further investigation is required to understand the reaction mechanism and optimization of chitosan/magnetite properties for improving seed germination and growth.

\section{Conclusions}

Iron plays an important role in the life activity of plants. Although it is one of the most common elements in the Earth`s crust, its availability for plants is not high. Recently, there has been an increased interest in iron nanoforms that positively affect the development of plants. However, little is known about the use of nanomagnetite in combination with other substances, for instance, chitosan, which is a well-known elicitor and widely used in agronomy. We decided to study their combined action and each component separately on the germination and seedling growth of wheat (Triticum aestivum L.). It was shown that the combined action of chitosan and nanomagnetite is 1.3 times more effective in seed germination compared to the control test. In contrast, the seed treatment with chitosan alone gave a slight increase in seed germination. No effect was revealed after the seed treatment with nanomagnetite. All seed treatment methods (chitosan, magnetite, and joint action) show an increase in plant growth, root, and shoot length. This increase is extremely dependent on the concentration of chitosan. A mechanism based on chitosan's ability to promote better transport of ferrous ions to plants is proposed to explain the synergistic effect of chitosan and nanomagnetite on plant growth. Therefore, future research should focus on understanding the details of chitosan's biochemical 
functions in combination with nanomagnetite, which will advance their application in agriculture.

\section{Funding}

This research received no external funding.

\section{Acknowledgments}

The authors wish to thank M. K. Beklemishev (Lomonosov Moscow State University, Department of Chemistry) for the valuable comments on this work.

\section{Conflicts of Interest}

The authors declare no conflict of interest.

\section{References}

1. Kabata-Pendias, A.; Pendias, H. Trace elements in soils and plants. $2^{\text {nd }}$ ed., CRC Press, Boca Raton, F.L. USA, 2001; pp. 403.

2. Rout, G.R. Role of iron in plant growth and metabolism. Reviews in Agricultural Science 2015, 3, 1-24, https://doi.org/10.7831/ras.3.1.

3. Adiele, J.G.; Egesi, C.; Nwaogu, A.S.; Kahya, S.S.; Ano, A.O. Available iron distribution in Nigerian soils - A review. Journal of Soil Science and Environmental Management 2015, 6, 68-71, https://doi.org/10.5897/JSSEM13.0418.

4. Kudryavceva, E.A.; Anilova, L.V.; Kuzmin, S.N.; Sharygina, M.V. Influence of various forms of iron on germination of seeds of Triticum Aestivum L.. Vestnik $O G U$ 2013, 155, 46-48.

5. Durán, N; Seabra, A.S. Metallic oxide nanoparticles: State of the art in biogenic syntheses and their mechanisms. Applied Microbiology and Biotechnology 2012, 95, 275-288, https://doi.org/10.1007/s00253012-4118-9.

6. Schüler, D; Frankel, R.B. Bacterial magnetosomes: microbiology, biomineralization and biotechnological applications. Appl. Nicrobiol. Biotechnol. 1999, 52, https://doi.org/10.1007/s002530051547.

7. Abdel-Bary, A.S.; Tolan, D.A.; Nassar, M.Y.; Taketsugu, T.; El-Nahas, A.M. Chitosan, magnetite, silicon dioxide, and graphene oxide nanocomposites: Synthesis, characterization, efficiency as cisplatin drug delivery, and DFT calculations. Int $J$ Biol Macromol. 2020, 154, 621-633, http://dx.doi.org/10.1016/j.ijbiomac.2020.03.106.

8. El Hadrami, A.; Adam, L.R.; El Hadrami, I.; Daayf, F. Chitosan in Plant Protection. Marine Drugs 2010, 8 , 968-87, https://doi.org/10.3390/md8040968.

9. Zohara, F.; Surovy, M.; Khatun, A.; Prince, M.; Akanda, M.; Islam, H.; Rahman, M.; Islam, T.; Hossain, M. Chitosan biostimulant controls infection of cucumber by Phytophthora capsici through suppression of asexual reproduction of the pathogen. Acta Agrobot. 2019, 72, 1763. https://doi.org/10.5586/aa.1763.

10. Akter Mukta, J.; Rahman, M.; As Sabir, A.; Gupta, D.R.; Surovy, M.Z.; Rahman, M.; Islam, M.T. Chitosan and plant probiotics application enhance growth and yield of strawberry. Biocatalysis Agric. Biotechnol. 2017, 11, 9-18, http://dx.doi.org/10.1016/j.bcab.2017.05.005.

11. Mehebub, M.; Mahmud, N.; Rahman, M.; Surovy, M.; Gupta, D.; Hasanuzzaman, M.; Rahman, M.; Islam, T. Chitosan biopolymer improves the fruit quality of litchi (Litchi chinensis Sonn.). Acta Agrobot. 2019, 72, https://doi.org/10.5586/aa.1773.

12. Xing, K.; Zhu, X.; Peng, X.; Qin, S. Chitosan antimicrobial and eliciting properties for pest control in agriculture: a review. Agronomy for Sustainable Development 2015, 35, 569-588, https://doi.org/10.1007/s13593-014-0252-3.

13. Schwertmann, U.; Cornell, R.M. Iron oxides in the laboratory: preparation and characterization. $2^{\text {nd }}$ ed.; Wiley-VCH: Weinheim, Germany, 2000; pp. 204, https://doi.org/10.1002/9783527613229.

14. IUSS Working Group WRB. World Reference Base for Soil Resources. International soil classification system for naming soils and creating legends for soil maps. World Soil Resources Reports FAO: Rome 2015, 106, 92.

15. Practical Manual on Colloid Chemistry for Higher Education Students. Kulichikhin, V.G. Eds.; Vuzovskii Uchebnik: Moscow, Russia, 2012; pp. 94-97.

16. Dey, S.; Kar, S.; Regon, P.; Panda, S.K. Physiology and Biochemistry of Fe Excess in Acidic Asian Soils on Crop Plants. Review article. SAINS TANAH - Journal of Soil Science and Agroclimatology 2019, 16, 112-126, https://dx.doi.org/10.20961/stjssa.v16i1.30456. 
17. Mahender, A.; Swamy, B.P.M.; Anandan, A.; Ali, J. Tolerance of Iron-Deficient and Toxic Soil Condition in Rice. Plants 2019, 8, https://doi.org/10.3390/plants8020031.

18. Nikolic, M.; Pavlovic, J. Plant Responses to Iron Deficiency and Toxicity and Iron Use Efficiency. In: Plant Micronutrient Use Efficiency Molecular and Genomic Perspectives in Crop Plants. Hossain, M.A.; Kamiya, T.; Burritt, D.; Tran, L.S.P.; Fujiwara T. Eds.; Academic Press: Massachusetts, USA, 2018; pp. 55-69, https://doi.org/10.1016/C2016-0-03180-7.

19. Mendoza, B.; Guananga, N.; Melendez, J.R.; Lowy, D.A. Differences in total iron content at various altitudes of Amazonian Andes soil in Ecuador. Flo00Research 2020, 9, 1https://doi.org/10.12688/f1000research.22411.1.

20. Bünemann, E.K.; Bongiorno, G.; Bai, Z.; Creamer, R.E.; De Deyn, G.; de Goede, R.; Fleskens, L.; Geissen, V.; Kuyper, T.W.; Mäder, P.; Pulleman, M.; Sukkel, W.; van Groenigen, J.W.; Brussaard, L. Soil quality A critical review. Soil Biology and Biochemistry 2018, 120, 105-125, https://doi.org/10.1016/j.soilbio.2018.01.030.

21. Neina, D. The Role of Soil pH in Plant Nutrition and Soil Remediation. Applied and Environmental Soil Science 2019, 2019, https://doi.org/10.1155/2019/5794869.

22. Wen, Y.; Xiao, J.; Goodman, B.A.; He, X. Effects of Organic Amendments on the Transformation of Fe (Oxyhydr)Oxides and Soil Organic Carbon Storage. Front. Earth Sci. 2019, 7, https://doi.org/10.3389/feart.2019.00257.

23. Lasota J.; Błońska, E.; Łyszczarz, S.; Tibbett, M. Forest Humus Type Governs Heavy Metal Accumulation in Specific Organic Matter Fractions. Water Air Soil Pollut. 2020, 231, https://doi.org/10.1007/s11270-0204450-0.

24. Li, X.; Volger, I.; Schwendenmann, L. Soil aggregation and soil fraction associated carbon under different vegetation types in a complex landscape. Soil Research 2019, 57, 215-227, https://doi.org/10.1071/sr18193.

25. Kheyrkhah, M.; Janmohammadi, M.; Abbasi, A.; Sabaghnia, N. The Effects of Micronutrients (Fe and Zn) and Beneficial Nano-Scaled Elements (Si And Ti) on Some Morphophysiological Characteristics of Oilseed Rape Hybrids. Agriculture (Pol'nohospodárstvo) 2018, 46, https://doi.org/10.2478/agri-2018-0012.

26. Claudio, C.; Iorio, E.d.; Liu, Q.; Jiang, Z.; Barrón, V. Iron Oxide Nanoparticles in Soils: Environmental and Agronomic Importance. Journal of Nanoscience and Nanotechnology 2017, 17, 4449-4460, https://doi.org/10.1166/jnn.2017.14197.

27. Pariona, N,; Martínez, Al.; Hernandez-Flores, H.; Clark-Tapia, R. Effect of magnetite nanoparticles on the germination and early growth of Quercus macdougallii. Science of the Total Environment 2017, 557, 869875, http://dx.doi.org/10.1016/j.scitotenv.2016.09.128.

28. Kataria, S.; Jain, M.; Rastogi, A.; Živčák, M.; Brestic, M.; Liu, S.; Tripathi, D.K. Role of nanoparticles on photosynthesis: avenues and applications. In: Nanomaterials in plants, algae and microorganisms: Concepts and Controversies. 1st ed.; Tripathi, D.K., Ahmad, P., Sharma, S., Chauhan, D.K., Dubey, N.K., Eds.; Academic Press: Dubey, UAE, Volume 2, 2019; pp. 103-127, https://doi.org/10.1016/C2016-0-00175-4.

29. Poddar, K.; Sarkar, D.; Sarkar, A. Nanoparticles on Photosynthesis of Plants: Effects and Role. In: Green Nanoparticles. the Nanotechnology in Life Sciences. Patra, J.; Fraceto, L.; Das, G.; Campos, E. Eds.;. Springer, 2020; pp. 273-287, https://doi.org/10.1007/978-3-030-39246-8_13.

30. Malerba, M.; Cerana, R. Recent Applications of Chitin- and Chitosan-Based Polymers in Plants. Polymers 2018, 10, https://doi.org/10.3390/polym11050839.

31. Orzali, L.; Corsi, B.; Forni, C.; Riccioni, L. Chitosan in Agriculture: A New Challenge for Managing Plant Disease. In: Biological Activities and Application of Marine Polysaccharides. Open access peer-reviewed chapter. 2017; https://doi.org/10.5772/66840.

32. Kong, M.; Chen, X.G.; Xing, K; Park, H.J. Antimicrobial properties of chitosan and mode of action: a state of the art review. Int. J. Food Microbiol. 2010, 144, 51-63, https://doi.org/10.1016/j.ijfoodmicro.2010.09.012.

33. Xing, K.; Zhu.X; Peng. X; Qin, S. Chitosan antimicrobial and eliciting properties for pest control in agriculture: A review. Agronomy for Sustainable Development 2014, 35, 569-588, https://doi.org/10.1007/s13593-014-0252-3.

34. Rajasree, R.; Rahate, K.P. An overview on various modifications of chitosan and it's applications. International journal of pharmaceutical sciences and research 2019, 1, https://doi.org/10.13040/IJPSR.0975-8232.4(11).4175-93.

35. Katiyar, D.; Hemantaranjan, A.; Singh, B.; Bhanu, A.N. A future perspective in crop protection: chitosan and its oligosaccharides. Adv Plants Agric Res. 2014, 1, 23-30, https://doi.org/10.15406/apar.2014.01.00006.

36. Zeng, D; Luo, X; Tu, R. Application of bioactive coatings based on chitosan for soybean seed protection. International Journal of Carbohydrate Chemistry Open Access 2012, 2012, 1-5, http://dx.doi.org/10.1155/2012/104565.

37. Dawood, M.G. Stimulating plant tolerance against abiotic stress through seed priming. In: Advances in seed priming. Rakshit, A.; Singh, H.B. Eds.; Springer: Singapore, 2018; pp. 147-183.

38. Iriti, M.; Varoni, E. Chitosan-induced antiviral activity and innate immunity in plants. Environmental Science and Pollution Research 2015, 22, 2935-2944, https://doi.org/10.1007/s11356-014-3571-7. 
39. Dutta, P. Seed priming: new vistas and contemporary perspectives. In: Advances in seed priming. Rakshit, Katiyar, D.; Hemantaranjan, A.; Singh, B.; Bhanu, A. A Future Perspective in Crop Protection: Chitosan and its Oligosaccharides. Advances in Plants \& Agricultural Research 2014, 1, 23-30, http://dx.doi.org/10.15406/apar.2014.01.00006.

40. Goy, R.C.; De Britto, D.; Assis, O.B.G. A Review of the Antimicrobial Activity of Chitosan. Polimeros 2009, 19, 241-247, http://dx.doi.org/10.1590/S0104-14282009000300013.

41. Guan, Y.-j.; Hu, J.; Wang, X.-j.; Shao, C.-X. Seed priming with chitosan improves maize germination and seedling growth in relation to physiological changes under low temperature stress. Journal of Zhejiang University SCIENCE B 2009, 10, 427-433, http://dx.doi.org/10.1631/jzus.B0820373.

42. Guan, Y.-J.; Hu, J.; Wang, X.-J.; Shao, C.-X. Seed priming with chitosan improves maize germination and seedling growth in relation to physiological changes under low temperature stress. J Zhejiang Univ Sci B 2009, 10, 427-433, https://doi.org/10.1631/jzus.B0820373.

43. Zeng, D.; Luo, X. Physiological Effects of Chitosan Coating on Wheat Growth and Activities of Protective Enzyme with Drought Tolerance. Open Journal of Soil Science 2012, 2, 282-288, http://dx.doi.org/10.4236/ojss.2012.23034.

44. Chandrasekaran, M.; Kim, D.; Chun, S.C. Antibacterial Activity of Chitosan Nanoparticles: A Review. Processes 2020, 8, https://doi.org/10.3390/pr8091173.

45. Oh, J.-W.; Chun, S.C.; Chandrasekaran, M. Preparation and in vitro characterization of chitosan nanoparticles and their broad-spectrum antifungal action compared to antibacterial activities against phytopathogens of tomato. Agronomy 2019, 9, https://doi.org/10.3390/agronomy9010021.

46. Maluin, F.N.; Hussein, M. Chitosan-based agronanochemicals as a sustainable alternative in crop protection. Molecules 2020, 25, 1611. https://doi.org/10.3390/molecules25071611.

47. Li, R.; He, J.; Xie, H.; Wang, W.; Bose, S.K.; Sun, Y.; Hu, J.; Yin, H. Effects of chitosan nanoparticles on seed germination and seedling growth of wheat (Triticum aestivum L.). International Journal of Biological Macromolecules 2019, 126, 91-100, https://doi.org/10.1016/j.ijbiomac.2018.12.118.

48. Mansouri, A.; Omidi, H. Effect of chitosan and iron oxide nanoparticles on germination and early growth indices of safflower under salinity stress. Thesis and Dissertation for MS and Ph.D degree. Seed Technology. 2017.

49. Kassem, A.; Ayoub, G.M.; Malaeb, L. Antibacterial activity of chitosan nanocomposites and carbon nanotubes: A review. Sci. Total. Environ. 2019, 668, 566-576, https://doi.org/10.1016/j.scitotenv.2019.02.446.

50. Agbodjato, N.A.; Noumavo, P.A.; Adjanohoun, A.; Agbessi, L.; Baba-Moussa, L. Synergistic Effects of Plant Growth Promoting Rhizobacteria and Chitosan on In Vitro Seeds Germination, Greenhouse Growth, and Nutrient Uptake of Maize (Zea mays L.). Biotechnology Research International Open Access 2016, 2016, https://doi.org/10.1155/2016/7830182.

51. Badawy, M.E.I.; Rabea, E.I. A Biopolymer Chitosan and Its Derivatives as Promising Antimicrobial Agents against Plant Pathogens and Their Applications in Crop Protection. International Journal of Carbohydrate Chemistry 2011, 2011, https://doi.org/10.1155/2011/460381.

52. Azovtseva, N.; Smagin, A.; Lazareva, E.V. The effect of chitosan on copper mobility in soddy-podzolic soils and porous media. Eurasian Soil Science 2004, 37, 402-408.

53. Rout, G.R. Role of iron in plant growth and metabolism. Reviews in Agricultural Science 2015, 3, 1-24, https://doi.org/10.7831/ras.3.1. 